\title{
Digestibilidade total e parcial e balanço nitrogenado em bovinos em pastejo no período das águas recebendo suplementos com nitrogênio não-proteico elou proteína verdadeira ${ }^{1}$
}

\author{
Viviane Aparecida Carli Costa ${ }^{2}$, Edenio Detmann ${ }^{3}$, Mário Fonseca Paulino ${ }^{3}$, Sebastião de \\ Campos Valadares Filho ${ }^{3}$, Lara Toledo Henriques ${ }^{4}$, Isabela Pena Carvalho de Carvalho ${ }^{5}$
}

\footnotetext{
1 Trabalho conduzido com apoio do CNPq, FAPEMIG (PPM) e INCT-Ciência Animal.

2 Laboratório de Zootecnia e Nutrição Animal, Universidade Estadual do Norte Fluminense, Campos dos Goytacazes-RJ.

${ }^{3}$ Departamento de Zootecnia, Universidade Federal de Viçosa, Viçosa-MG. Pesquisador do CNPq e do INCT-Ciência Animal.

${ }^{4}$ Centro de Ciências Agrárias, Universidade Federal da Paraíba, Areia-PB.

${ }^{5}$ Departamento de Zootecnia, Universidade Estadual Paulista, Jaboticabal-SP.
}

RESUMO - Objetivou-se avaliar o efeito de diferentes relações entre proteína verdadeira e nitrogênio não-proteico sobre a digestibilidade, a síntese de proteína microbiana e o balanço de compostos nitrogenados em bovinos em pastejo durante o período das águas. Foram utilizados cinco novilhos mestiços Holandês $\times$ Zebu, castrados, com peso vivo inicial de $335 \pm 35 \mathrm{~kg}$ fistulados no rúmen e no abomaso. Os tratamentos foram: controle (somente pasto); e suplementos com ureia; com 2/3 de compostos nitrogenados oriundos da ureia e 1/3 de compostos nitrogenados oriundos da albumina; com 1/3 de compostos nitrogenados oriundos da ureia e 2/3 de compostos nitrogenados oriundos da albumina; e com albumina. Foram fornecidos $200 \mathrm{~g} /$ dia de proteína bruta (PB) a partir dos suplementos. O experimento foi conduzido segundo delineamento em quadrado latino $5 \times 5$, com cinco períodos experimentais, cada um de 15 dias. A suplementação não afetou os coeficientes de digestibilidade total nem o teor de nutrientes digestíveis totais da dieta; elevou as estimativas do coeficiente de digestibilidade aparente ruminal da PB, que migraram de negativa, no tratamento controle, para positivas, porém não diferentes de zero, nos tratamentos envolvendo suplementação. O fornecimento de suplementos elevou a concentração de nitrogênio amoniacal ruminal. O balanço de compostos nitrogenados aumentou com a suplementação. A substituição de ureia por albumina influenciou de forma cúbica o balanço de compostos nitrogenados, cuja estimativa foi maior para o suplemento com 1/3 de PB oriunda da ureia. A eficiência de síntese microbiana no rúmen não foi influenciada pelo fornecimento ou pela composição dos suplementos. A suplementação de bovinos em pastejo com fontes de compostos nitrogenados degradáveis durante o período das águas amplia a eficiência de uso do pasto, principalmente por ampliar a retenção de compostos nitrogenados no organismo.

Palavras-chave: albumina, digestibilidade parcial, nitrogênio amoniacal, suplementação, ureia

\section{Total and partial digestibility and nitrogen balance in grazing cattle supplemented with non-protein and, or true protein nitrogen during the rainy season}

\begin{abstract}
The objective of this study was to evaluate the effect of different true protein:non-protein nitrogen ratios in supplements on digestibility, microbial protein synthesis and nitrogen balance in grazing cattle during rainy season. Five crossbred Holstein $\times$ Zebu steers, averaging $335 \pm 35 \mathrm{~kg}$ of body weight and fitted with rumen and abomasum canullae were used. The treatments were: control (only pasture), and supplements based on urea, 2/3 of nitrogenous compounds from urea and 1/3 of nitrogenous compounds from albumin, $1 / 3$ of nitrogenous compounds from urea and 2/3 of nitrogenous compounds from albumin, and albumin. Two hundred grams of crude protein (CP) were daily supplied from supplements. The experiment was carried out according to a $5 \times 5$ Latin square design, with five 15-day experimental periods. Supplementation did not affect the total digestibility coefficients or the diet content of total digestible nutrients. Supplementation increased ruminal apparent digestibility coefficient of CP, which moved from negative for the control treatment to positive, but not different from zero, for treatments involving supplementation. Supplementation increased the rumen ammonia nitrogen concentration. Nitrogen balance was enhanced by supplementation. The replacement of urea by albumin caused a cubic effect on the nitrogen balance, with the higher value obtained at $1 / 3$ of supplemental $\mathrm{CP}$ as urea. The efficiency of microbial protein synthesis was not influenced by supplementation or supplement composition. Supplementation with ruminal degradable nitrogenous compounds for grazing cattle during the rainy season increases the efficiency of use of pasture mainly by improving the body nitrogenous compounds retention.
\end{abstract}

Key Words: albumin, ammonia nitrogen, partial digestibility, supplementation, urea

Recebido em 16/9/2010 e aprovado em 6/7/2011. 


\section{Introdução}

O aproveitamento das forragens pelos bovinos está diretamente relacionado à atividade microbiana ruminal, notadamente sobre os compostos fibrosos, a qual depende do nível de compostos nitrogenados presentes no meio. Em gramíneas tropicais, são observadas elevadas porções de compostos nitrogenados insolúveis em detergente neutro (Paulino et al., 2002), os quais, por serem de lenta e incompleta degradação (Sniffen et al., 1992), podem ocasionar carência de compostos nitrogenados para os microrganismos ruminais, limitando a produção de proteína microbiana, a degradação dos compostos fibrosos e, consequentemente, o desempenho animal.

Contudo, a atividade microbiana ruminal sobre os compostos fibrosos não depende apenas do nível de compostos nitrogenados presentes no meio, mas também na forma como se encontram disponíveis. As bactérias que degradam carboidratos não-fibrosos (CNF) utilizam dois terços de seus substratos nitrogenados na forma de peptídeos e aminoácidos e um terço na forma de amônia, potencialmente produzida a partir de fontes nitrogenadas prontamente degradáveis no rúmen, como a ureia. Por sua vez, bactérias que degradam carboidratos fibrosos utilizam preferencialmente amônia como substrato nitrogenado para crescimento (Russell et al., 1992).

Assim, considerando a coexistência de ambos os grupos de microrganismos, torna-se necessário o fornecimento de forma equilibrada de compostos nitrogenados, garantindo a disponibilidade de nitrogênio amoniacal, peptídeos e ácidos graxos de cadeia ramificada necessários ao crescimento harmônico das populações microbianas presentes no rúmen. Dessa forma, poderia ser definido, via suplementação, o perfil ideal para o crescimento microbiano global no rúmen a partir do fornecimento de mistura de compostos nitrogenados proteicos e não-proteicos.

Resultados de pesquisas conduzidas em condições tropicais permitem evidenciar que a suplementação proteica, incluindo o uso de ureia como principal composto nitrogenado dos suplementos, pode melhorar o desempenho animal durante o período das águas (Figueiredo et al., 2008; Paulino et al., 2008).

Contudo, informações sobre a influência da suplementação com base em compostos nitrogenados sobre a utilização de forragens tropicais de alta qualidade sob pastejo são ainda escassas na literatura nacional. Assim, objetivou-se avaliar os efeitos de diferentes relações entre proteína verdadeira e nitrogênio não-proteico em suplementos para bovinos mantidos em pastejo de capimbraquiária (Brachiaria decumbens Stapf.) durante o período das águas sobre os coeficientes de digestibilidade totais e parciais, a síntese de proteína microbiana e o balanço de compostos nitrogenados.

\section{Material e Métodos}

O experimento foi conduzido no Setor de Bovinocultura de Corte do Departamento de Zootecnia da Universidade Federal de Viçosa, Minas Gerais, entre dezembro de 2007 e março de 2008 (período das águas).

Foram utilizados cinco novilhos mestiços Holandês $\times$ Zebu, castrados, com peso vivo (PV) inicial de $335 \pm 35 \mathrm{~kg}$ fistulados no rúmen e no abomaso. A área experimental foi composta de cinco piquetes de capim-braquiária, com 0,34 ha cada, contendo bebedouro e comedouro coberto, sendo cada animal manejado em um piquete. Paralelamente aos piquetes, situava-se o curral de manejo, no qual foram realizadas as coletas nos animais. Todos os animais tiveram acesso irrestrito a água e mistura mineral completa.

Foram avaliados os seguintes tratamentos: controle (MM) (somente mistura mineral); suplementação com ureia (U); suplementação com 2/3 de compostos nitrogenados oriundos da ureia e $1 / 3$ de compostos nitrogenados oriundos da albumina (2/3U); suplementação com $1 / 3$ de compostos nitrogenados oriundos da ureia e 2/3 de compostos nitrogenados oriundos da albumina (1/3U); e suplementação com albumina (A).

Os suplementos foram fornecidos de forma a suprir 200 g de proteína bruta (PB) a cada animal diariamente às 12 h, via fístula ruminal. Este nível de suplementação foi fornecido para suprir aproximadamente $30 \%$ das exigências de proteína degradável no rúmen, tomando-se como base um novilho zebuíno castrado com 350 kg de PV e ganho esperado de $1 \mathrm{~kg} /$ dia (Valadares Filho et al., 2006).

As fontes alimentares utilizadas na formulação dos suplementos foram escolhidas de forma a contrastarem-se fontes e proporções de compostos nitrogenados de origem proteica (albumina) e não-proteica (ureia:sulfato de amônio, 9:1).

O experimento foi conduzido segundo delineamento em quadrado latino $5 \times 5$, em cinco períodos experimentais com 15 dias cada, sendo os cinco primeiros dias destinados à adaptação dos animais à suplementação.

No primeiro dia de cada período experimental, quantificou-se a massa de forragem disponível em cada piquete por intermédio do corte rente ao solo de cinco áreas delimitadas por um quadrado de dimensões $0,5 \times 0,5 \mathrm{~m}$, selecionadas ao acaso em cada piquete. As amostras, depois de pesadas, foram avaliadas quanto ao teor de matéria seca (MS) (Silva \& Queiroz, 2002). A disponibilidade média de 
forragem foi de 11,3; 14,1; 12,9; 14,2 e 13,4 t MS/ha para os períodos experimentais sequencialmente.

A avaliação do pasto ingerido pelos animais foi realizada no primeiro, quinto e décimo dias de cada período experimental por simulação manual de pastejo. As amostras foram secas sob ventilação forçada $\left(60^{\circ} \mathrm{C}\right)$, processadas em moinho de facas ( 1 e $2 \mathrm{~mm}$ ) e posteriormente compostas, como base no peso seco ao ar, por piquete e período experimental.

Para estimação da excreção fecal, utilizou-se dióxido de titânio como indicador externo, fornecido na quantidade de $20 \mathrm{~g} /$ dia a cada animal, às $12 \mathrm{~h}$, via fístula ruminal, entre o primeiro e oitavo dias de cada período experimental. As coletas fecais foram realizadas de acordo com o cronograma: $6^{0}$ dia, às 8 h e 14 h; $7^{0}$ dia, às 10 h e 16 h; e $8^{0}$ dia, às 12 h e $18 \mathrm{~h}$. Simultaneamente à coleta fecal, foram tomadas amostras de digesta abomasal. As amostras de fezes e digesta abomasal foram secas sob ventilação forçada $\left(60^{\circ} \mathrm{C}\right)$ e processadas em moinho de facas (1 e $2 \mathrm{~mm}$ ). Posteriormente, elaboraram-se amostras compostas, com base no peso seco ao ar, por animal e período experimental.

Para avaliação do pH e da concentração de nitrogênio amoniacal ruminal (NAR), foram realizadas, no nono dia do período experimental, coletas de líquido ruminal às 6 , 12,18 e $24 \mathrm{~h}$. As amostras foram coletadas manualmente na interface líquido:sólido do ambiente ruminal, filtradas por camada tripla de gaze e submetidas à avaliação do $\mathrm{pH}$ em potenciômetro digital. Em seguida, separou-se alíquota de $40 \mathrm{~mL}$, a qual foi fixada com $1 \mathrm{~mL}$ de $\mathrm{H}_{2} \mathrm{SO}_{4}$ (1:1) e congelada $\left(-20^{\circ} \mathrm{C}\right)$ para posterior análise.

No nono dia de cada período experimental, foi realizada coleta de conteúdo ruminal para isolamento de microrganismos ruminais (Cecava et al., 1990). As amostras foram tomadas imediatamente antes e seis horas após o fornecimento do suplemento (às 12 h e 18 h).

No 15 을, foram realizadas coletas de urina, na forma de amostras spot, em micção espontânea dos animais, aproximadamente duas horas antes (10 h) e quatro horas após (16 h) o fornecimento dos suplementos. As amostras foram filtradas em gaze e uma alíquota de $10 \mathrm{~mL}$ foi separada e diluída com $40 \mathrm{~mL}$ de ácido sulfúrico $(0,036 \mathrm{~N})$ para quantificação das concentrações urinárias de creatinina, ureia e nitrogênio total. Simultaneamente à amostragem urinária, foram coletadas amostras de sangue diretamente da veia jugular utilizando-se tubos com vácuo e gel acelerador de coagulação (BD Vacuntainer ${ }^{\circledR}$ SST II Advance). O sangue foi imediatamente centrifugado a $2.700 \mathrm{x}$ g por 15 minutos para obtenção do soro, sendo este armazenado $\left(-20^{\circ} \mathrm{C}\right)$ para posterior avaliação do nível sérico de ureia.
As amostras de pasto obtidas via simulação manual, digesta abomasal e fezes ( $1 \mathrm{~mm}$ ) foram avaliadas quanto aos teores de MS, matéria orgânica (MO), $\mathrm{PB}$, extrato etéreo (EE), fibra em detergente ácido (FDA) e lignina $\left(\mathrm{H}_{2} \mathrm{SO}_{4} 72 \%\right.$ p/p), segundo técnicas descritas por Silva \& Queiroz (2002). Os teores de fibra em detergente neutro (FDN) foram estimados segundo recomendações de Mertens (2002). As correções referentes aos teores de cinzas e proteína contidos na FDN e na FDA foram realizadas conforme recomendações de Mertens (2002) e Licitra et al. (1996), respectivamente. Os suplementos foram avaliados quanto aos teores de MS, MO, PB e EE, segundo técnicas descritas acima (Tabela 1).

Os teores de CNF foram obtidos segundo Detmann \& Valadares Filho (2010):

$$
C N F=M O-[E E+F D N c p+(P B-P B u+U)]
$$

em que: $\mathrm{CNF}=$ teor de carboidratos não-fibrosos (\%); MO = teor de matéria orgânica (\%); EE = teor de extrato etéreo (\%); FDNcp = teor de fibra em detergente neutro corrigida para cinzas e proteína (\%); PB = teor de proteína bruta (\%); $\mathrm{PBu}=$ teor de proteína bruta a partir da ureia (\%); $\mathrm{U}=$ teor de ureia (\%).

As amostras fecais foram avaliadas por colorimetria quanto ao teor de dióxido de titânio, segundo método descrito por Titgmeyer et al. (2001). A excreção fecal foi estimada como a relação entre dose e concentração fecal do indicador.

As estimativas de consumo voluntário e fluxo abomasal foram obtidas utilizando-se a FDN indigestível (FDNi) como indicador interno, quantificada por procedimento de incubação in situ por 240 horas em amostras processadas a $2 \mathrm{~mm}$, segundo recomendações de Casali et al. (2008).

A concentração de NAR foi quantificada de acordo com a técnica colorimétrica proposta por Chaney \& Marbach (1962) e os valores obtidos nos diferentes tempos de amostragem foram combinados por animal, produzindo-se, ao final, valor único, representativo da média diária de concentração de NAR. Combinação similar foi conduzida sobre os valores de $\mathrm{pH}$ ruminal.

As amostras de microrganismos ruminais foram avaliadas quanto aos teores de PB (Silva \& Queiroz, 2002) e bases púricas (Ushida et al., 1985). Contudo, problemas foram detectados nas estimativas de concentração de bases púricas nos microrganismos. Dessa forma, para cálculo da produção microbiana, utilizou-se a estimativa média da relação $\mathrm{N}_{\mathrm{RNA}}: \mathrm{N}_{\text {total }}$ nos microrganismos ruminais relatada por Valadares Filho (1995) (0,176 g/g).

As amostras de soro, após descongelamento, foram compostas por animal e período experimental e analisadas quanto aos teores de ureia, segundo método enzimáticocolorimétrico (Bioclin ${ }^{\circledR}$ K047). 
As amostras de urina, depois de descongeladas, foram compostas por animal e período experimental e analisadas quanto aos teores de creatinina, segundo o método de Jaffé modificado (Bioclin ${ }^{\circledR} \mathrm{K} 016$-1), ureia, como descrito para as amostras de soro, e nitrogênio total, segundo o método de Kjeldhal (Silva \& Queiroz, 2002).

O volume urinário total foi estimado como a relação entre concentração de creatinina na urina e sua excreção por unidade de PV, segundo Chizzotti et al. (2006).

Após a análise de variância, a soma de quadrados de tratamentos foi decomposta por contrastes ortogonais (Tabela 2). Os procedimentos estatísticos foram conduzidos por intermédio do programa SAS (Statistical Analysis System, versão 9.1), adotando-se 0,10 como nível crítico de probabilidade para o erro tipo I.

Tabela 1 - Composição química do pasto e dos suplementos

\begin{tabular}{|c|c|c|c|c|c|}
\hline \multirow[t]{2}{*}{ Item } & \multicolumn{4}{|c|}{ Suplemento } & \multirow[b]{2}{*}{ Pasto $^{1}$} \\
\hline & Ureia & $2 / 3$ ureia $+1 / 3$ albumina & $1 / 3$ ureia $+2 / 3$ albumina & Albumina & \\
\hline Matéria seca, \% matéria natural & 98,20 & 97,24 & 96,26 & 95,30 & $22,05 \pm 0,87$ \\
\hline Proteína bruta, \% MS & 256,11 & 197,83 & 137,79 & 79,52 & $9,99 \pm 0,32$ \\
\hline Extrato etéreo, \% MS & 0,0 & 0,81 & 1,64 & 2,45 & $1,54 \pm 0,06$ \\
\hline Fibra em detergente neutro, \% MS & - & - & - & - & $71,42 \pm 0,61$ \\
\hline Carboidratos não-fibrosos, \% MS $^{2}$ & 0,0 & 5,13 & 10,66 & 16,03 & $15,75 \pm 0,47$ \\
\hline Fibra em detergente ácido, \% MS & - & - & - & - & $41,69 \pm 0,51$ \\
\hline FDAcp, \% MS & - & - & - & - & $30,31 \pm 0,83$ \\
\hline PIDA, \% PB & - & - & - & - & $7,90 \pm 0,33$ \\
\hline Lignina, \% MS & - & - & - & - & $4,05 \pm 0,12$ \\
\hline FDNi, \% MS & - & - & - & - & $17,81 \pm 0,45$ \\
\hline
\end{tabular}

MS = matéria seca; $\mathrm{MO}$ = matéria orgânica; FDNcp = fibra em detergente neutro corrigida para cinzas e proteína; PIDN = proteína insolúvel em detergente neutro; FDAcp = fibra em detergente ácido corrigida para cinzas e proteína; PIDA = proteína insolúvel em detergente ácido; FDNi = fibra em detergente neutro indigestível.

${ }^{1}$ Média \pm erro-padrão da média (amostras obtidas por simulação manual de pastejo).

Tabela 2 - Distribuição dos coeficientes empregados nos contrastes

\begin{tabular}{lccccc}
\hline Contraste $^{1}$ & \multicolumn{4}{c}{ Tratamento } \\
\cline { 2 - 6 } & Controle & Ureia & $2 / 3$ ureia $+1 / 3$ albumina & $1 / 3$ ureia $+2 / 3$ albumina & Albumina \\
\hline CO & 4 & -1 & -1 & -1 & 1 \\
Linear & 0 & -3 & -1 & 1 & -1 \\
Quadrático & 0 & -1 & 1 & -3 & -1 \\
Cúbico & 0 & -1 & 3 & 1 \\
\hline
\end{tabular}

${ }^{1} \mathrm{CO}$ = controle versus suplementos; os efeitos linear, quadrático e cúbico são referentes à substituição da ureia por albumina no suplemento.

\section{Resultados}

A suplementação não afetou ( $\mathrm{P}>0,10)$ os coeficientes de digestibilidade total ou o nível dietético de nutrientes digestíveis totais (NDT), com exceção do coeficiente de digestibilidade total da $\mathrm{PB}$, que aumentou $(\mathrm{P}<0,10)$ com o fornecimento de suplementos (Tabela 3).

A variação na composição dos suplementos teve efeito cúbico $(\mathrm{P}<0,10)$ sobre o coeficiente de digestibilidade total da FDNcp, o qual pode ser atribuído ao aumento causado pela utilização de 2/3 de PB a partir da ureia em comparação aos demais suplementos (Tabela 3).

A suplementação elevou $(\mathrm{P}<0,10)$ as estimativas do coeficiente de digestibilidade ruminal da $\mathrm{PB}$, que migraram de negativa $(\mathrm{P}<0,10)$, no tratamento controle, para positivas, porém não diferentes de zero $(\mathrm{P}>0,10)$, nos tratamentos com suplementação (Tabela 3).

A alteração na composição dos suplementos afetou de forma linear $(\mathrm{P}<0,10)$ o coeficiente de digestibilidade ruminal da MS, o que indica tendência de redução à medida que a albumina foi adicionada ao suplemento (Tabela 3). Nenhum outro coeficiente de digestibilidade ruminal foi afetado $(\mathrm{P}>0,10)$ pela suplementação ou pela composição dos suplementos.

A suplementação não afetou $(\mathrm{P}>0,10)$ os coeficientes de digestibilidade intestinal, contudo, efeitos lineares positivos da substituição da ureia por albumina foram observados $(\mathrm{P}<0,10)$ sobre os coeficientes de digestibilidade intestinal da MS e do EE (Tabela 3).

$\mathrm{O}$ fornecimento de suplementos elevou o $\mathrm{pH}$ ruminal $(\mathrm{P}<0,10)$. Por outro lado, a substituição da ureia por 
Tabela 3 - Médias, coeficientes de variação (CV) e níveis descritivos de probabilidade para contrastes (valor-P) para os coeficientes de digestibilidade ruminal, intestinal e total e teor dietético de nutrientes digestíveis totais em função dos diferentes tratamentos

\begin{tabular}{|c|c|c|c|c|c|c|c|c|c|c|}
\hline \multirow[t]{2}{*}{ Item } & \multicolumn{5}{|c|}{ Tratamento } & \multirow[t]{2}{*}{ CV (\%) } & \multicolumn{4}{|c|}{ Valor-P ${ }^{1}$} \\
\hline & Controle & Ureia & $\begin{array}{c}\text { 2/3 ureia }+ \\
1 / 3 \text { albumina }\end{array}$ & $\begin{array}{c}\text { 1/3 ureia }+ \\
2 / 3 \text { albumina }\end{array}$ & Albumina & & $\mathrm{CO}$ & $\mathrm{L}$ & Q & $\mathrm{C}$ \\
\hline Matéria seca & 69,94 & 73,25 & 77,03 & 73,75 & 60,71 & 15,8 & 0,831 & 0,099 & 0,140 & 0,915 \\
\hline Matéria orgânica & 80,18 & 82,25 & 84,72 & 81,28 & 71,65 & 13,4 & 0,971 & 0,132 & 0,255 & 0,991 \\
\hline Proteína bruta ${ }^{3}$ & $-22,56^{*}$ & $9,92^{\text {ns }}$ & $15,95^{\mathrm{ns}}$ & $17,34^{\mathrm{ns}}$ & $7,74^{\mathrm{ns}}$ & 371,2 & 0,009 & 0,911 & 0,469 & 0,898 \\
\hline Carboidratos não-fibrosos & 65,16 & 77,49 & 80,52 & 48,62 & 28,79 & 93,1 & 0,856 & 0,333 & 0,787 & 0,777 \\
\hline & & & & & Intestinal $^{2}$ & & & & & \\
\hline Matéria seca & 30,06 & 26,75 & 23,92 & 26,25 & 39,29 & 36,9 & 0,856 & 0,089 & 0,127 & 0,801 \\
\hline Matéria orgânica & 19,82 & 17,75 & 16,35 & 18,72 & 28,35 & 51,1 & 0,921 & 0,124 & 0,256 & 0,868 \\
\hline Proteína bruta & 52,99 & 53,64 & 54,20 & 54,74 & 59,82 & 13,4 & 0,493 & 0,220 & 0,506 & 0,764 \\
\hline Extrato etéreo & 66,29 & 65,53 & 65,57 & 66,95 & 72,81 & 6,1 & 0,502 & 0,016 & 0,140 & 0,712 \\
\hline Matéria orgânica & 62,13 & 60,47 & 66,26 & 61,11 & 62,67 & 9,1 & 0,867 & 0,904 & 0,448 & 0,185 \\
\hline Proteína bruta & 45,16 & 58,05 & 62,00 & 62,40 & 63,27 & 8,8 & $<0,001$ & 0,148 & 0,534 & 0,724 \\
\hline Extrato etéreo & 47,46 & 48,87 & 58,09 & 49,40 & 58,86 & 23,4 & 0,323 & 0,405 & 0,983 & 0,169 \\
\hline FDNcp & 74,50 & 72,50 & 78,29 & 71,17 & 73,34 & 7,6 & 0,816 & 0,694 & 0,506 & 0,097 \\
\hline Carboidratos não-fibrosos & 31,03 & 22,56 & 23,80 & 28,57 & 23,38 & 36,6 & 0,220 & 0,722 & 0,500 & 0,541 \\
\hline Nutrientes digestíveis totais & 58,24 & 57,44 & 63,09 & 57,50 & 57,63 & 9,4 & 0,812 & 0,659 & 0,287 & 0,151 \\
\hline
\end{tabular}

${ }^{1} \mathrm{CO}$ = controle versus suplementos; L, Q e C = efeitos linear, quadrático e cúbico da substituição da ureia por albumina.

${ }^{2}$ EE e PB expressos com percentual do que chegou ao local de digestão; para as demais variáveis, utilizou-se como referência o percentual do total digerido.

$3(*)$ e (ns) = significativamente e não-significativamente diferente de zero pelo teste $t(\alpha=0,10)$.

albumina nos suplementos implicou efeito cúbico sobre o $\mathrm{pH}$ ruminal $(\mathrm{P}<0,10)$, com queda nas estimativas em $1 / 3$ de substituição, elevação em 2/3 de substituição e nova queda com a substituição completa por albumina (Tabela 4).

A concentração de nitrogênio amoniacal ruminal aumentou $(\mathrm{P}<0,10)$ com a suplementação. Contudo, nenhum efeito foi verificado $(\mathrm{P}>0,10)$ na variação na composição dos suplementos. Os valores médios diários para animais que não receberam suplemento e aqueles sob suplementação foram de 9,77 e 15,04 mg NAR/dL de líquido ruminal (Tabela 4).

O consumo de nitrogênio sofreu efeito positivo da suplementação $(\mathrm{P}<0,10)$ e efeito linear $(\mathrm{P}<0,10)$ da substituição da ureia por albumina nos suplementos. Por outro lado, a excreção fecal de nitrogênio não foi afetada $(\mathrm{P}>0,10)$ pela suplementação nem pela composição dos suplementos. O fornecimento de suplementos não alterou $(\mathrm{P}>0,10)$ a excreção de nitrogênio urinário. Contudo, esta variável foi afetada de forma quadrática $(\mathrm{P}<0,10)$ pela substituição da ureia por albumina, pois houve redução das estimativas para o suplemento composto por $1 / 3$ de PB oriunda da ureia (Tabela 4).

Os balanços nitrogenados absoluto (g/dia) e relativo (g nitrogênio retido/g nitrogênio ingerido) aumentaram com a suplementação $(\mathrm{P}<0,10)$, com valores médios para os animais que não receberam suplemento e aqueles sob suplementação, de 21,33 e 71,78 g/dia e 0,180 e 0,409 g/g, respectivamente (Tabela 4). Adicionalmente, a substituição de ureia por albumina teve efeito cúbico sobre o balanço de nitrogênio $(\mathrm{P}<0,10)$, refletindo a maior estimativa observada com 1/3 de PB oriunda da ureia no suplemento. $\mathrm{O}$ balanço nitrogenado relativo comportou-se de forma linear positiva $(\mathrm{P}<0,10)$ com a substituição de ureia por albumina (Tabela 4).

A excreção urinária de nitrogênio ureico (EUNU) não foi afetada $(\mathrm{P}>0,10)$ pelo fornecimento de suplementos nem pela variação na composição dos suplementos (Tabela 4), apresentando valor médio de 22,79 g/dia, equivalendo, em média, a $67,1 \%$ dos compostos nitrogenados totais presentes na urina.

A concentração sérica de nitrogênio ureico (NUS) aumentou com a suplementação $(\mathrm{P}<0,10)$, contudo não foi afetada pela alteração na composição dos suplementos $(\mathrm{P}>0,10)$. Quando expressa em relação ao consumo de nitrogênio (NUS:CN), reduziu com a suplementação $(\mathrm{P}<0,10)$. Neste caso, a substituição da ureia por albumina causou decréscimo linear $(\mathrm{P}<0,10)$ na relação NUS:CN (Tabela 4). 
Tabela 4 - Médias, coeficientes de variação (CV) e níveis descritivos de probabilidade para contrastes (valor-P) para o pH ruminal, concentração de nitrogênio amoniacal ruminal e para as características de utilização dos compostos nitrogenados em função dos tratamentos

\begin{tabular}{|c|c|c|c|c|c|c|c|c|c|c|}
\hline \multirow[t]{2}{*}{ Item } & \multicolumn{5}{|c|}{ Tratamento } & \multirow[t]{2}{*}{ CV (\%) } & \multicolumn{4}{|c|}{ Valor-P } \\
\hline & Controle & Ureia & $\begin{array}{l}2 / 3 \text { ureia }+ \\
1 / 3 \text { albumina }\end{array}$ & $\begin{array}{l}1 / 3 \text { ureia }+ \\
2 / 3 \text { albumina }\end{array}$ & Albumina & & $\mathrm{CO}$ & $\mathrm{L}$ & Q & $\mathrm{C}$ \\
\hline $\mathrm{N}$-amoniacal ruminal, mg/dL & 9,77 & 14,73 & 14,83 & 17,93 & 12,67 & 26,6 & 0,015 & 0,685 & 0,134 & 0,153 \\
\hline Consumo de nitrogênio, g/dia & 113,10 & 159,66 & 159,29 & 180,97 & 181,97 & 9,6 & $<0,001$ & 0,020 & 0,925 & 0,187 \\
\hline Excreção fecal de nitrogênio, g/dia & 61,25 & 65,61 & 61,56 & 65,92 & 63,35 & 14,1 & 0,537 & 0,902 & 0,863 & 0,410 \\
\hline Balanço nitrogenado aparente, g/dia & 21,33 & 56,62 & 62,45 & 89,69 & 78,37 & 23,0 & $<0,001$ & 0,010 & 0,202 & 0,060 \\
\hline $\begin{array}{l}\text { Balanço nitrogenado relativo, } \\
\text { g/g N digerido }\end{array}$ & 0,180 & 0,348 & 0,390 & 0,481 & 0,415 & 20,6 & $<0,001$ & 0,096 & 0,144 & 0,194 \\
\hline N-ureico no soro (NUS), mg/dL & 10,33 & 12,94 & 11,78 & 11,78 & 11,97 & 11,0 & 0,017 & 0,282 & 0,268 & 0,712 \\
\hline $\mathrm{N}$-ureico no soro:consumo de $\mathrm{N}$ & 0,0938 & 0,0814 & 0,0752 & 0,0676 & 0,0643 & 13,6 & 0,002 & 0,027 & 0,781 & 0,797 \\
\hline $\begin{array}{l}\mathrm{N} \text {-ureico no soro: } \mathrm{N} \text {-amoniacal } \\
\text { ruminal }\end{array}$ & 1,0975 & 0,9186 & 0,9352 & 0,7631 & 0,8593 & 22,6 & 0,055 & 0,461 & 0,695 & 0,305 \\
\hline $\begin{array}{l}\mathrm{N} \text { nos microrganismos ruminais, } \\
\% \text { da MS }\end{array}$ & 7,73 & 8,17 & 8,98 & 7,95 & 7,88 & 11,4 & 0,289 & 0,328 & 0,314 & 0,157 \\
\hline
\end{tabular}

NDT = nutrientes digestíveis totais.

CO = controle versus suplementos; L, Q e C = efeitos linear, quadrático e cúbico da substituição da ureia por albumina.

A relação NUS:NAR reduziu $(P<0,10)$ com a suplementação, mas não foi alterada pela variação na composição dos suplementos $(\mathrm{P}>0,10)$.

O fluxo abomasal de nitrogênio microbiano (NMIC) aumentou, embora de forma não-significativa $(\mathrm{P}<0,11)$, pelo fornecimento de suplementos. Os valores médios foram de 76,65 e 87,05 g/dia para os animais dos grupos controle e com suplementação, respectivamente. Adicionalmente, A eficiência de síntese de proteína microbiana (EFM) e o teor de compostos nitrogenados nos microrganismos ruminais não foram influenciados $(\mathrm{P}>0,10)$ pelo fornecimento ou pela composição dos suplementos (Tabela 4), apresentando valor médio de 115,7 g PB microbiana/kg de NDT e 8,14\% de nitrogênio, com base na MS.

\section{Discussão}

De forma geral, poucos foram os efeitos da suplementação sobre os coeficientes de digestibilidade totais e parciais, com exceção da PB, os quais serão discutidos posteriormente. Embora se tenha observado queda na proporção da MS digerida no rúmen com a substituição de ureia por albumina, este efeito foi compensado pela relação linear positiva da proporção de albumina no suplemento sobre o coeficiente de digestibilidade intestinal da MS, o que culminou em estimativas similares do coeficiente de digestibilidade total da MS (Tabela 4).
A utilização de 2/3 da PB suplementar na forma de ureia tem sido apontada em condições tropicais como ponto em que haveria maior estímulo às atividades dos microrganismos fibrolíticos, no senso de se promover o equilíbrio no fornecimento de precursores nitrogenados, principalmente na forma de amônia, e de outros substratos, como ácidos graxos de cadeia ramificada, produzidos a partir da degradação de proteína verdadeira (Zorzi et al., 2009). Este estímulo à utilização da FDN acarretou efeito cúbico da composição dos suplementos sobre o coeficiente de digestibilidade total da FDN, cuja maior estimativa foi observada com a utilização de 2/3 da PB do suplemento na forma de ureia, embora sem implicações no teor de NDT na dieta (Tabela 3).

O efeito positivo mais proeminente da suplementação observado neste estudo pode ser atribuído à elevação no balanço nitrogenado, o qual aumentou de 18,0 para, em média, 40,9\% do nitrogênio total ingerido (Tabela 4). Este efeito acarretaria diretamente incremento no ganho de peso de animais em produção.

Em experimentos com animais em produção durante o período das águas em condições tropicais, constitui resposta comum a não alteração do consumo de forragem e do coeficiente de digestibilidade da FDN, com concomitante elevação do ganho de peso quando suplementos proteicos ( $>50 \%$ PB) são ofertados (Zervoudakis, 2003; Zervoudakis et al., 2008; Porto, 2009). Os resultados obtidos confirmam esse 
comportamento, uma vez que o fornecimento de suplementos não alterou o consumo de pasto (Costa et al., 2011).

Em grande parte dos trabalhos, a ampliação do ganho de peso (e, por analogia, do balanço de compostos nitrogenados) de animais mantidos em pastos de alta qualidade com suplementação proteica está associada à elevação da concentração de NAR (Zervoudakis, 2003; Moraes et al., 2006; Paulino et al., 2006; Zervoudakis et al., 2008). Neste estudo, o fornecimento de suplementos elevou a concentração diária de NAR de 9,77 para, em média, 15,04 mg/dL (Tabela 4).

Segundo Detmann et al. (2009), 15 mg de NAR/dL de fluido ruminal são necessários para que se maximize a produção microbiana no rúmen de bovinos alimentados com forragem tropical de baixa qualidade. De acordo com estes autores, esta concentração de NAR é superior ao necessário para minimização dos entraves físicos ao consumo (8 mg/dL), o que corrobora, ao menos em parte, a ausência de efeitos sobre a ingestão de FDN (Costa et al., 2011). Contudo, ajustamentos metabólicos demandariam concentração excedente de NAR (15 mg/dL) de forma a reduzir o desconforto animal, sob a ótica de controle multifatorial do consumo, e maximizar a utilização dos nutrientes oriundos da forragem no metabolismo animal (Detmann et al., 2009; 2010).

Embora sem efeito significativo $(\mathrm{P}<0,11)$, a suplementação incrementou a produção de compostos nitrogenados microbianos em cerca de 10,4 g N/dia ou 13,6\% em relação ao tratamento controle (Tabela 4). Considerando-se a contribuição da proteína microbiana em termos de aminoácidos absorvidos no intestino delgado, associada à constância entre tratamentos quanto ao nível de NDT na dieta (Tabela 4) e ao consumo de NDT (Costa et al., 2011), haveria maior relação proteína metabolizável:energia metabolizável no organismo animal, o que propiciaria maior retenção de nitrogênio corporal. Isto é suportado pela correlação positiva $(r=0,726 ; \mathrm{P}<0,10)$ entre NMIC e BN (Tabela 5).

Ressalta-se que, mesmo sem diferenças significativas entre suplementos, maior estimativa de produção microbiana foi observada com a utilização de $1 / 3$ da PB suplementar na forma de ureia, o que parece ter contribuído, ao menos em parte, para o maior balanço de compostos nitrogenados observado neste tratamento (Tabela 4). Isto aparentemente contradiz o maior estímulo sobre o crescimento microbiano sobre a FDN com a utilização de 2/3 da PB na forma de ureia, como apresentado por outros autores (Zorzi et al., 2009) e verificado neste estudo (Tabela 3). Contudo, o ecossistema ruminal é composto por várias populações microbianas (Russell, 2002), assim, a utilização de $1 / 3$ de PB na forma de ureia e 2/3 na forma de proteína verdadeira pode ter acarretado otimização global do crescimento microbiano, propiciando ponto de equilíbrio entre populações fibrolíticas e não-fibrolíticas.

De forma geral, o balanço de compostos nitrogenados foi influenciado primariamente pela entrada de nitrogênio no sistema, o que é evidenciado pela correlação positiva $(r=0,950 ; \mathrm{P}<0,10)$ com o consumo de nitrogênio (Tabela 5). Reitera-se que a suplementação não afetou as perdas

Tabela 5 - Coeficientes de correlação linear de Pearson entre as variáveis: fluxo intestinal de nitrogênio microbiano (NMIC), balanço nitrogenado aparente (BN), concentração de nitrogênio ureico no soro, concentração de nitrogênio amoniacal ruminal (NAR), consumo de nitrogênio (CN), coeficiente de digestibilidade ruminal da proteína bruta (DRPB), excreção fecal de nitrogênio (EFN), excreção urinária de nitrogênio (EUN), excreção urinária de nitrogênio ureico (EUNU)

\begin{tabular}{|c|c|c|c|c|c|c|c|c|}
\hline \multirow[b]{2}{*}{ Variável ${ }^{1,2}$} & \multicolumn{8}{|c|}{ Variável ${ }^{1,2}$} \\
\hline & $\mathrm{BN}$ & NUS & NAR & $\mathrm{CN}$ & DRPB & EFN & EUN & EUNU \\
\hline \multirow[t]{2}{*}{ NMIC } & 0,726 & 0,120 & 0,589 & 0,760 & 0,657 & 0,355 & 0,156 & $-0,184$ \\
\hline & 0,012 & 0,724 & 0,057 & 0,007 & 0,028 & 0,284 & 0,646 & 0,588 \\
\hline \multirow[t]{2}{*}{$\mathrm{BN}$} & - & 0,326 & 0,774 & 0,950 & 0,809 & 0,115 & 0,071 & 0,273 \\
\hline & & 0,327 & 0,005 & $<0,001$ & 0,003 & 0,737 & 0,835 & 0,417 \\
\hline \multirow[t]{2}{*}{ NUS } & & - & 0,428 & 0,451 & 0,568 & 0,179 & 0,711 & $-0,009$ \\
\hline & & & 0,189 & 0,164 & 0,069 & 0,598 & 0,014 & 0,978 \\
\hline \multirow[t]{2}{*}{ NAR } & & & - & 0,809 & 0,679 & 0,412 & 0,115 & $-0,075$ \\
\hline & & & & 0,003 & 0,023 & 0,028 & 0,737 & 0,826 \\
\hline \multirow[t]{2}{*}{$\mathrm{CN}$} & & & & - & 0,875 & 0,383 & 0,328 & 0,180 \\
\hline & & & & & $<0,001$ & 0,245 & 0,325 & 0,596 \\
\hline \multirow[t]{2}{*}{ DRPB } & & & & & - & 0,281 & 0,476 & 0,123 \\
\hline & & & & & & 0,403 & 0,139 & 0,719 \\
\hline \multirow[t]{2}{*}{ EFN } & & & & & & - & 0,498 & $-0,212$ \\
\hline & & & & & & & 0,119 & 0,531 \\
\hline \multirow[t]{2}{*}{ EUN } & & & & & & & - & $-0,170$ \\
\hline & & & & & & & & 0,617 \\
\hline
\end{tabular}

\footnotetext{
${ }^{1}$ Os valores subescritos correspondem aos níveis descritivos de probabilidade para erro tipo I associado às hipóteses: $H_{0}: \rho=0$; $H_{a}: \rho \neq 1$.
}

${ }^{2}$ Os coeficientes de correlação foram ajustados para os efeitos de animal e período experimental. 
nitrogenadas urinárias e fecais (Tabela 4), as quais não apresentaram associação com o balanço nitrogenado $(\mathrm{P}>0,10)$ (Tabela 5).

Contudo, a associação entre consumo e balanço de compostos nitrogenados não deve ser interpretada de forma direta, uma vez que nem todo o nitrogênio presente nos suplementos (e.g. ureia e sulfato de amônio) pode ser diretamente incorporado no organismo animal. Neste sentido, a associação entre balanço de compostos nitrogenados e o consumo de nitrogênio deve ser enfatizada indiretamente pela associação deste com outras variáveis do metabolismo dos compostos nitrogenados.

O consumo de nitrogênio se associou positivamente $(\mathrm{r}=0,760 ; \mathrm{P}<0,10)$ com a produção microbiana, e esta, por sua vez, se associou positivamente $(r=0,726 ; P<0,10)$ com o balanço de compostos nitrogenados (Tabela 5). Isso indica que a ampliação no consumo total de nitrogênio afeta o balanço nitrogenado por estimular o fluxo de compostos nitrogenados microbianos no intestino delgado, o que pode ser reflexo da associação positiva $(r=0,589 ; \mathrm{P}<0,10)$ com a concentração de NAR (Tabela 5).

Contudo, assumindo-se que 60\% do nitrogênio microbiano está na forma de proteína verdadeira e que esta apresenta $100 \%$ de digestibilidade intestinal (Sniffen et al., 1992), o aumento numérico médio no fluxo de nitrogênio microbiano responderia por cerca de 6,0; 18,9; 13,5 e 10,2\% do incremento do balanço nitrogenado para os suplementos compostos por ureia, $2 / 3$ de ureia, $1 / 3$ de ureia e albumina, respectivamente (média de 12,2\%). Esse comportamento indica que outros mecanismos, além do fornecimento de proteína no intestino, estão associados à suplementação com fontes proteicas degradáveis, contribuindo para a ampliação no balanço de compostos nitrogenados no animal.

Hafley et al. (1993), ao suplementarem bovinos em pasto de alta qualidade (10,5\% de PB) com fontes proteicas degradáveis no rúmen, verificaram ampliação no ganho de peso em relação ao tratamento controle, sem suplementação $(0,95 \times 1,03 \mathrm{~kg} / \mathrm{dia})$. Contudo, ao acrescentarem ao suplemento fontes proteicas nãodegradáveis (o que aumentaria o suprimento de proteína no intestino além do adicional de proteína microbiana), não notaram efeito sobre o desempenho animal em comparação ao fornecimento exclusivo de proteína degradável (1,08 kg/dia). Ressalta-se que o suprimento somente de fontes proteicas não-degradáveis não ampliou o ganho de peso em relação ao controle $(0,97 \mathrm{~kg} / \mathrm{dia})$. Esses resultados reforçam a hipótese da ação de mecanismos que não envolvem a ampliação direta do aporte de proteína metabolizável.
Por outro lado, mesmo obtendo-se incrementos no ganho de peso ou balanço nitrogenado com o aumento no suprimento de proteína degradável, estes podem não estar associados a incrementos no suprimento de proteína microbiana (Marini \& Van Amburgh, 2003; Porto, 2009).

Embora a concentração de NAR tenha se correlacionado positivamente com a produção de nitrogênio microbiano $(r=0,589 ; P<0,10)$, correlação mais forte foi observada entre NAR e o balanço de compostos nitrogenados $(r=0,774$; $\mathrm{P}<0,10$ ), o que parece indicar que a disponibilidade de nitrogênio amoniacal no rúmen afeta o balanço nitrogenado por outras vias além do estímulo ao crescimento microbiano.

O suprimento de NAR é provido pela degradação da proteína dietética e pelos eventos de reciclagem de nitrogênio na forma de ureia via saliva e epitélio ruminal (Van Soest, 1994). Comumente, a reciclagem de nitrogênio é assumida como significativa somente se o consumo de nitrogênio for baixo (Huntington \& Archibeque, 2000), assumindo papel de mecanismo para atendimento das exigências microbianas quando as exigências do hospedeiro são baixas (Van Soest, 1994). Dessa forma, em animais alimentados com níveis proteicos considerados não-limitantes ao crescimento microbiano, como os observados neste estudo para os animais mantidos sem suplementação (aproximadamente 9\%), não se esperaria participação significativa da reciclagem como aquela observada sob condições de baixos níveis proteicos (Figueiras et al., 2010).

Contudo, o coeficiente de digestibilidade ruminal da $\mathrm{PB}$, no caso de animais que não receberam suplemento, foi negativo (Tabela 4). Nesta condição, o fluxo de nitrogênio ao abomaso é superior ao consumo de nitrogênio, ou seja, o rúmen está em situação de balanço negativo de compostos nitrogenados e a reciclagem parece estar provendo quantidades significativas de nitrogênio ao ambiente ruminal. Assim, seu papel parece ser significativo em animais sem suplementação. Neste estudo, verificou-se que coeficientes de digestibilidade ruminal negativos da PB são obtidos com níveis de NAR inferiores a $10,91 \mathrm{mg} / \mathrm{dL}$. Estímulos sobre este parâmetro são obtidos $(\mathrm{P}<0,10)$ até o nível de 12,56 mg NAR/dL. A partir deste ponto, não são mais observadas $(P>0,10)$ alterações sobre o coeficiente de digestibilidade ruminal da PB (Figura 1). A conversão desses valores em PB dietética (Figura 2) indica que 10,52 e 11,62\% de PB são necessários para se anular e maximizar o coeficiente de digestibilidade ruminal aparente da PB, respectivamente.

A ureia transferida do sangue para o ambiente ruminal é rapidamente degradada pelas bactérias ureolíticas aderidas ao epitélio ruminal. Isso faz com que a concentração de ureia no rúmen seja extremamente baixa em relação à concentração 
sanguínea, garantindo gradiente favorável para sua transferência (Van Soest, 1994). Neste contexto, o mecanismo de transferência é muitas vezes assumido como simplesmente passivo.

No entanto, a intensidade de transferência de ureia não deve ser vista simplesmente como efeito do ambiente de crescimento microbiano, mas como processo de interação entre o microrganismo e o hospedeiro com regulação específica (Waterlow, 2006). Neste sentido, a taxa de transferência de ureia do sangue para o rúmen é regulada pela expressão das ureases microbiana e epitelial (Chalupa et al., 1970; Cheng \& Wallace, 1979) e pela síntese de transportadores (ou facilitadores de transporte) de ureia no epitélio ruminal (Marini \& Van Amburgh, 2003; Marini et al., 2004).

A flora ureolítica da parede do rúmen constitui exemplo de população de bactérias simbióticas cuja atividade enzimática está envolvida na regulação de uma função

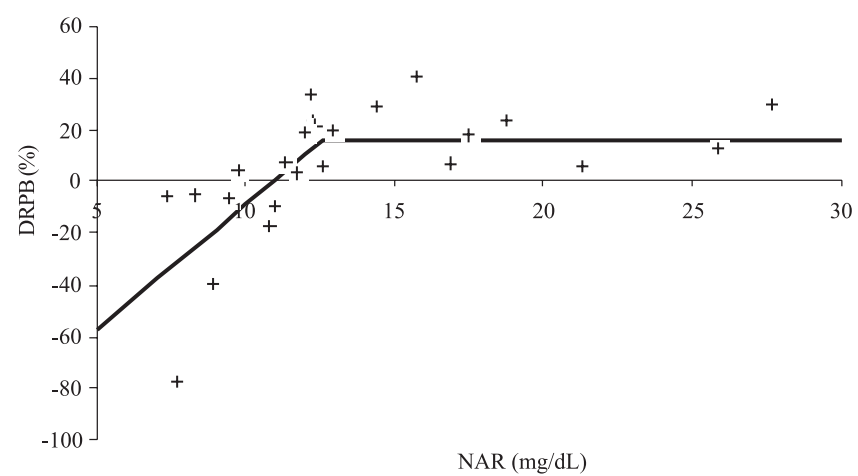

Figura 1 - Relação entre a concentração de nitrogênio amoniacal ruminal (NAR) e o coeficiente de digestibilidade ruminal da proteína bruta (DRPB) $(\hat{Y}=-105,7336+9,692 X$, $\forall X<12,5582 ; \hat{Y}=15,9865, \forall X \geq 12,5582$; $\left.\mathrm{s}_{\mathrm{xy}}=15,88\right)$.

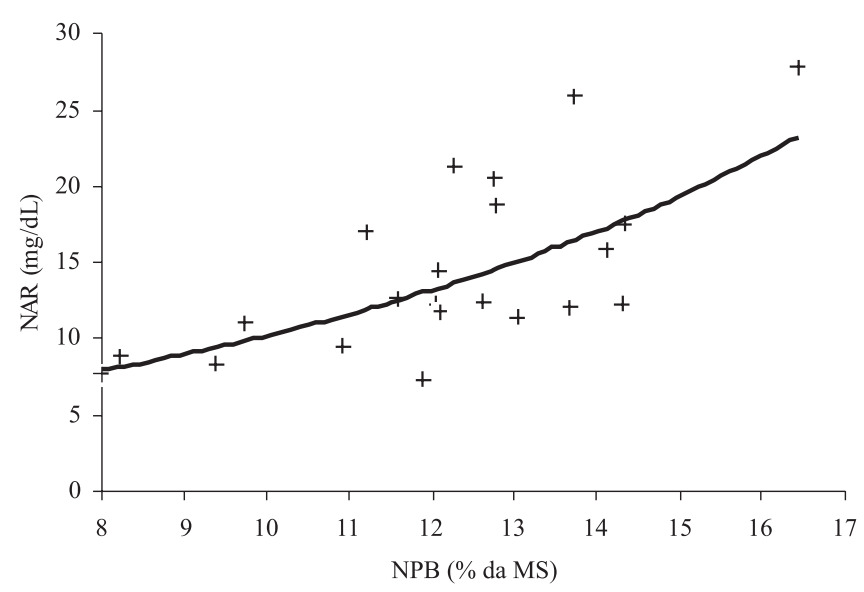

Figura 2 - Relação entre o nível de proteína bruta na dieta (NPB) e a concentração de nitrogênio amoniacal ruminal (NAR) $\left(\hat{Y}=2,8439 \mathrm{e}^{0,1278 \mathrm{X}} ; \mathrm{s}_{\mathrm{xy}}=4,14\right)$. essencial do animal (a reciclagem de nitrogênio) (Cheng \& Wallace, 1979). A atividade ureolítica no epitélio ruminal está positivamente associada à transferência de ureia do sangue, ou seja, quanto maior a atividade ureolítica, maior a transferência (Chalupa et al.; 1970; Cheng \& Wallace, 1979; Kennedy et al., 1981).

Entre vários mecanismos envolvidos na regulação da atividade ureolítica microbiana e epitelial, a concentração de NAR assume papel fundamental (NRC, 1985; Huntington \& Arquibeque, 2000; Marini \& Van Amburgh, 2003). A expressão de urease pelas bactérias facultativas do epitélio ruminal é regulada negativamente pela concentração de NAR, ou seja, animais com baixa amônia ruminal terão maior taxa de transferência de ureia pela maior expressão da urease (Bunting et al., 1989). Assim, a intensificação ou redução do processo de transferência de ureia para o rúmen pela urease bacteriana é indiretamente controlada pela concentração de NAR (Cheng \& Wallace, 1979).

Neste contexto, pode-se afirmar que baixas concentrações de NAR ampliarão a reciclagem de ureia para o rúmen (Harmeyer \& Martens, 1980; Marini \& Van Amburgh, 2003; Marini et al., 2004), mecanismo que parece ser responsável pelo balanço negativo de compostos nitrogenados no rúmen em animais que não recebem suplemento (Tabela 3) e que, provavelmente, resulta de tentativa do animal em propiciar melhores condições para o crescimento microbiano com objetivo de adequar a relação proteína:energia no metabolismo (Detmann et al., 2009).

Isso daria ao rúmen de animais que não recebem suplemento o status de dreno de ureia sanguínea. Segundo Kennedy \& Milligan (1978), a máxima transferência de ureia para o rúmen em bovinos é obtida com 5 a 8 mg NAR/dL. Neste caso, a suplementação com compostos nitrogenados prontamente degradáveis, ampliando a concentração de NAR, reduziria o dreno de ureia pelo rúmen e, consequentemente, a participação percentual da reciclagem no ambiente ruminal (NRC, 1985), culminando em balanço de nitrogênio ruminal positivo (Tabela 3; Figura 1).

Ampliações do dreno ruminal de ureia quando menores concentrações de NAR são implementadas foram verificadas por outros autores mediante avaliação da depuração sanguínea de ureia pelo rúmen (Kennedy \& Milligan, 1980; Marini \& Van Amburgh, 2003).

A depuração sanguínea total de ureia é influenciada pelo balanço entre as depurações renal e ruminal (Marini \& Van Amburgh, 2003). Apesar da correlação positiva $(r=0,711$; $\mathrm{P}<0,10$ ) observada entre NUS e excreção total de nitrogênio na urina, não houve associação $(P>0,10)$ entre NUS e excreção urinária de ureia (Tabela 5). Logo, a depuração 
renal de ureia parece não ter sido alterada entre tratamentos, reforçando a hipótese de dreno ruminal de ureia.

Devido à maior deficiência dietética de compostos nitrogenados observada durante o período seco em comparação ao período das águas, argumentos poderiam ser tecidos no sentido de que o dreno ruminal de ureia é significativo somente na seca, em virtude das menores concentrações de NAR. Contudo, em adição à amônia ruminal, a degradação ruminal de matéria orgânica tem efeito direto e positivo sobre a transferência de ureia para o rúmen (Kennedy \& Milligan, 1980; Kennedy et al., 1981), possível reflexo do maior crescimento microbiano com forragens de melhor qualidade.

Segundo Detmann et al. (2010), durante o período das águas, a massa de matéria orgânica degradada no rúmen pode ser superior em cerca de $80 \%$ em relação ao período da seca, o que implicaria ampliação da demanda de ureia para manutenção do crescimento microbiano no rúmen, reforçando a hipótese de que o dreno de ureia pelo rúmen é significativo durante o período das águas. Embora não haja correlação entre NUS e a expressão dos mecanismos de regulação de transferência de ureia para o rúmen (Kennedy \& Milligan, 1980), o que é reforçado pela ausência de correlação entre NUS e NAR ( $\mathrm{P}>0,10$; Tabela 5), o pool sanguíneo de ureia funciona como fornecedor para rúmen.

O espaço de ureia corporal constitui fração constante do peso vivo, sendo NUS representante da concentração de ureia neste espaço (Marini \& Van Amburgh, 2003). O pool corporal de ureia seria dado pelo produto entre espaço e concentração. Em delineamento quadrado latino completo, como utilizado neste estudo, todos os tratamentos são aplicados a todos os animais; logo, as diferenças entre animais são controladas, fazendo com que as estimativas médias de tratamentos sejam expressas homogeneamente em relação ao efeito de animal. Assim, a dimensão do espaço de ureia seria a mesma para todos os tratamentos. Portanto, o pool de ureia seria dado pelo produto do espaço, que seria constante, pela concentração de NUS. Desta forma, a variação na concentração representaria diretamente a variação no pool, pois seria a única variável no produto.

Sob este pressuposto, o fornecimento de suplementos ampliou o pool absoluto de ureia no organismo dos animais (Tabela 4), o que concorda com os resultados de outros autores (Harmeyer \& Martens, 1980; Marini \& Van Amburgh, 2003; Marini et al., 2004). Contudo, o pool de ureia relativo à massa total de nitrogênio ingerido (dado pela relação NUS:CN) foi maior nos animais que não receberam suplemento, comprovando maior proporção nitrogênio circulante em relação a cada unidade de nitrogênio ingerida.
O maior pool relativo de ureia nos animais sem suplementação pode estar refletindo o maior dreno ruminal de ureia, confirmado pela maior relação NUS:NAR nesses animais (Tabela 4). Embora o pool de ureia esteja positivamente relacionado ao maior consumo de nitrogênio (Marini \& Van Amburgh, 2003), a concentração de ureia no pool é controlada homeostaticamente para manutenção de funções vitais (Van Soest, 1994; Marini et al., 2004). Assim, nos animais que não receberam suplemento, o maior pool relativo parece indicar que o dreno ruminal de ureia exigiria maior síntese de ureia hepática para manutenção da homeostase sanguínea.

Mesmo parecendo um ciclo fútil, a síntese de ureia no fígado e sua posterior degradação no trato gastrintestinal pode ser considerada necessária para prover NAR para a síntese microbiana, constituindo mecanismo adaptativo para retenção de nitrogênio no sistema (Marini \& Van Amburgh, 2003). A síntese hepática de ureia envolve a assimilação de dois átomos de nitrogênio: um a partir da amônia mitocondrial via síntese de carbamilfosfato; e outro a partir do aspartato citoplasmático (Lindsay \& Reynolds, 2005). Os pools de transaminação mitocondrial e citoplasmático estão normalmente em equilíbrio, resultando no fato de os dois átomos de nitrogênio da ureia poderem ser oriundos da amônia ou de aminoácidos por intermédio da ação reversível da glutamato desidrogenase. Contudo, sob condições de alto fluxo de ureia, o suprimento mitocondrial de amônia pode não ser suficiente para suprir os dois átomos de nitrogênio, resultando na ampliação do uso de aminoácidos para síntese de ureia (Parker et al., 1995). Assim, o dreno de ureia definido pelo rúmen sob baixa concentração de NAR poderia implicar maior utilização de aminoácidos para síntese de ureia.

A utilização de aminoácidos para síntese de ureia pode estar associada à baixa retenção de nitrogênio em ruminantes alimentados com forragens (Parker et al., 1995). Lobley et al. (1995) verificaram que o aumento no ciclo da ureia está associado à utilização de aminoácidos para síntese da ureia. Em adição, Marini \& Van Amburgh (2003) verificaram que o aumento no suprimento de nitrogênio ampliou a síntese hepática de ureia a partir da própria ureia dietética, o que, indiretamente, reduziria a participação de outras fontes de nitrogênio, como aminoácidos).

Os aminoácidos utilizados para síntese de ureia são retirados do pool sanguíneo de aminoácidos livres (Waterlow, 1999). Por sua vez, o pool de aminoácidos circulantes é mantido homeostaticamente (Van Soest, 1994). Assim, na presença de maior captura hepática de aminoácidos, os aminoácidos absorvidos no intestino 
delgado seriam utilizados para manter o pool de aminoácidos livres e não seriam utilizados para síntese de tecido (Detmann et al., 2010).

Assim, a partir dos pressupostos apresentados, a suplementação com fontes proteicas degradáveis ampliaria a concentração de NAR e reduziria a demanda de ureia pelo rúmen. Isso acarretaria menor utilização de aminoácidos para síntese hepática de ureia, ampliando a disponibilidade de precursores para síntese de proteína corporal, elevando o balanço nitrogenado dos animais sob suplementação.

O maior balanço nitrogenado observado com a utilização de 1/3 da PB oriunda da ureia poderia ser suportado por esses mecanismos discutidos, uma vez que, em comparação aos demais suplementos, foi o que propiciou maior concentração de NAR e maior produção de nitrogênio microbiano (Tabela 4).

\section{Conclusões}

A suplementação de bovinos em pastejo com fontes de compostos nitrogenados degradáveis durante o período das águas amplia a eficiência de uso do pasto por elevar a concentração de nitrogênio amoniacal ruminal, o que reflete indiretamente em aumento do balanço nitrogenado.

\section{Referências}

BUNTING, L.D.; BOLING, J.A.; MacKOWN, C.T. et al. Effect of dietary protein level on nitrogen metabolism in the growing bovine: II Diffusion into and utilization of endogenous urea nitrogen in the rumen. Journal of Animal Science, v.67, p.820-826, 1989.

CASALI, A.O.; DETMANN, E.; VALADARES FILHO, S.C. et al. Influência do tempo de incubação e do tamanho de partículas sobre os teores de compostos indigestíveis em alimentos e fezes bovinas obtidos por procedimentos in situ. Revista Brasileira de Zootecnia, v.37, p.335-342, 2008.

CECAVA, J.M.; MERCHEN, N.R.; GAY, L.C. et al. Composition of ruminal bacteria harvested from steers as influenced by dietary energy level, feeding frequency, and isolation techniques. Journal of Dairy Science, v.73, p.2480-2488, 1990.

CHALUPA, W.C.; CLARK, J.; OPLIGER, P. et al. Ammonia metabolism in rumen bacteria and mucosa from sheep fed soy protein or urea. Journal of Nutrition, v.100, p.161-169, 1970.

CHANEY, A.L.; MARBACH, E.P. Modified reagents for determination of urea and ammonia. Clinical Chemistry, v.8, p.130-132, 1962.

CHENG, K.J.; WALLACE, R.J. The mechanism of passage of endogenous urea through the rumen wall and the role of ureolytic epithelial bacteria in the urea flux. British Journal of Nutrition, v.42, p.553-557, 1979.

CHIZZOTTI, M.L.; VALADARES FILHO, S.C.; VALADARES, R.F.D. et al. Consumo, digestibilidade e excreção de uréia e derivados de purinas em novilhas de diferentes pesos. Revista Brasileira de Zootecnia, v.35, p.1813-1821, 2006.

COSTA, V.A.C.; DETMANN, E.; PAULINO, M.F. et al. Consumo e dinâmica ruminal da fibra em detergente neutro em bovinos em pastejo no período das águas suplementados com nitrogênio não-protéico e/ou proteína verdadeira. Revista Brasileira de Zootecnia, v.40, n.12, p.2805-2814, 2011.

DETMANN, E.; PAULINO, M.F.; MANTOVANi, H.C. et al. Parameterization of ruminal fibre degradation in low-quality tropical forage using Michaelis-Menten kinetics. Livestock Science, v.126, p.136-146, 2009.

DETMANN, E.; PAULINO, M.F.; VALADARES FILHO, S.C. Otimização do uso de recursos forrageiros basais. In: SIMPÓSIO DE PRODUÇÃO DE GADO DE CORTE, 7., 2010, Viçosa, MG. Anais... Viçosa, MG: DZO-UFV, 2010. p.191-240.

DETMANN, E.; VALADARES FILHO, S.C. On the estimation of non-fibrous carbohydrates in feeds and diets. Arquivo Brasileiro de Medicina Veterinária e Zootecnia, v.62, p.980-984, 2010.

FIGUEIRAS, J.F.; DETMANN, E.; PAULINO, M.F. et al. Intake and digestibility in cattle under grazing during dry season supplemented with nitrogenous compounds. Revista Brasileira de Zootecnia, v.39, p1303-1312, 2010.

FIGUEIREDO, D.M.; PAULINO, M.F.; DETMANN, E. et al. Fontes de proteína em suplementos múltiplos para bovinos em pastejo no período das águas. Revista Brasileira de Zootecnia, v.37, p.2222-2232, 2008.

HAFLEY, J.L.; ANDERSON, B.E; KLOPFENSTEIN, T.J. Supplementation of growing cattle grazing warm-season grass with proteins of various ruminal degradabilities. Journal of Animal Science, v.71, p.522-529, 1993.

HARMEYER, J.; MARTENS, H. Aspects of urea metabolism in ruminants with reference to the goat. Journal of Dairy Science, v.63, p.1707-1728, 1980.

HUNTINGTON, G.B.; ARCHIBEQUE, S.L. Practical aspects of urea and ammonia metabolism in ruminants. Journal of Animal Science, v.77, p.1x-11x, 2000.

KENNEDY, M.P.; MILLIGAN, L.P. The effects of dietary sucrose and the concentrations of plasma urea and rumen ammonia on the degradation of urea in the gastrointestinal tract of cattle. British Journal of Nutrition, v.43, p.125-140, 1980.

KENNEDY, P.M.; CLARKE, R.T.J.; MILLIGAN, L.P. Influences of dietary sucrose and urea on transfer of endogenous urea to the rumen of sheep and numbers of epithelial bacteria. British Journal of Nutrition, v.46, p.533-541, 1981.

LICITRA, G.; HERNANDES, T.M.; Van SOEST, P.J. Standardization of procedures for nitrogen fractionation of ruminant feeds. Animal Feed Science and Technology, v.57, p.347-358, 1996.

LINDSAY, D.B.; REYNOLDS, C.K. Metabolism of the portal-drained viscera and liver. In: DIJKSTRA, J.; FORBES, J.M.; FRANCE, J. (Eds.) Quantitative aspects of ruminant digestion and metabolism. 2.ed. Wallingford: CABI Publishing, 2005. p.373-398.

LOBLEY, G.E.; CONNELL, A.; LOMAX, M.A. et al. Hepatic detoxification of ammonia in the ovine liver: possible consequences for amino acid catabolism. British Journal of Nutrition, v.73, p.667-685, 1995.

MARINI, J.C.; Van AMBURGH, M.E. Nitrogen metabolism and recycling in Holstein heifers. Journal of Animal Science, v.81, p.545-552, 2003.

MARINI, J.C.; KLEIN, J.D.; SANDS, J.M. et al. Effect of nitrogen intake on nitrogen recycling and urea transporters abundance in lambs. Journal of Animal Science, v.82, p.1157-1164, 2004.

MERTENS, D.R. Gravimetric determination of amylase-treated neutral detergent fiber in feeds with refluxing in beakers or crucibles: collaborative study. Journal of AOAC International, v.85, p.1217-1240, 2002.

MORAES, E.H.B.K.; PAULINO, M.F.; ZERVOUDAKIS, J.T et al. Níveis de proteína em suplementos para novilhos mestiços em pastejo durante o período de transição seca/águas. Revista Brasileira de Zootecnia, v.35, p.2135-2143, 2006.

NATIONAL RESEARCH COUNCIL - NRC. Ruminant nitrogen usage. Washington, D.C.: Academic Press, 1985. 138p. 
PARKER, D.S.; LOMAX, M.A.; SEAL, C.J. et al. Metabolic implications of ammonia production in the ruminant. Proceedings of Nutrition Society, v.54, p.549-563, 1995.

PAULINO, M.F.; ZERVOUDAKIS, J.T.; MORAES, E.H.B.K. et al. Bovinocultura de ciclo curto em pastagens. In: SIMPÓSIO DE PRODUÇÃO DE GADO DE CORTE, 3., 2002 Viçosa, MG. Anais... Viçosa, MG: DZO-UFV, 2002. p.153-196.

PAULINO, M.F.; MORAES, E.H.B.K; ZERVOUDAKIS, J.T. et al. Terminação de novilhos mestiços leiteiros sob pastejo, no período das águas, recebendo suplementação com soja. Revista Brasileira de Zootecnia, v.35, p.154-158, 2006.

PAULINO, M.F.; DETMANN, E.; VALENTE, E.E.L. et al. Nutrição de bovinos em pastejo. In: SIMPÓSIO SOBRE MANEJO ESTRATÉGICO DA PASTAGEM, 4., 2008, Viçosa, MG. Anais... Viçosa, MG: DZO-UFV, 2008. p.131-169.

PORTO, M.O. Suplementos múltiplos para bovinos de corte nas fases de cria, recria e terminação em pastagens de Brachiaria decumbens. 2009. 140f. Tese (Doutorado em Zootecnia) - Universidade Federal de Viçosa, Viçosa, MG.

RUSSELL, J.B.; O’CONNOR, J.D.; FOX D.G. et al. A net carbohydrate and protein system for evaluating cattle diets: I. Ruminal fermentation. Journal of Animal Science, v.70, p.3551-3561, 1992

RUSSELL, J.B. Rumen microbiology and its role in ruminant nutrition. Ithaca: James B. Russell, 2002. 119p.

SILVA, D.J.; QUEIROZ, A.C. Análise de alimentos: métodos químicos e biológicos. 3.ed. Viçosa, MG: Editora UFV, 2002. 235p.

SNIFFEN, C.J.; O’CONNOR, J.D.; Van SOEST, P.J. et al. A net carbohydrate and protein system for evaluating cattle diets: II Carbohydrate and protein availability. Journal of Animal Science, v.70, p.3562-3577, 1992.

TITGEMEYER, E.C.; ARMENDARIZ, C.K.; BINDEL, D.J. et al. Evaluation of titanium dioxide as a digestibility marker for cattle. Journal of Animal Science, v.79, p.1059-1063, 2001.

USHIDA, K.; LASSALAS, B.; JOUANY, J.P. Determination of assay parameters for RNA analysis in bacterial and duodenal samples by spectrophotometry. Influence of treatment and preservation. Reproduction Nutrition Development, v.25, p.1037-1046, 1985.

VALADARES FILHO, S.C. Eficiência de síntese de proteína microbiana, degradação ruminal e digestibilidade intestinal da proteína bruta, em bovinos. In: SIMPÓSIO INTERNACIONAL SOBRE EXIGÊNCIAS NUTRICIONAIS DE RUMINANTES, 1995, Viçosa, MG. Anais... Viçosa, MG: DZO-UFV, 1995. p.355-388.

VALADARES FILHO, S.C.; PAULINO, P.V.R.; VALADARES, R.F.D. et al. Exigências nutricionais de zebuínos no Brasil. II. Proteína. In: VALADARES FILHO, S.C.; PAULINO, P.V.R.; MAGALHÃES, K.A. (Eds.) Exigências nutricionais de zebuínos e tabelas de composição de alimentos BRCORTE. Viçosa, MG: DZO-UFV, 2006. p.75-84.

Van SOEST, P.J. Nutritional ecology of the ruminant. 2.ed. Ithaca: Cornell University Press, 1994. 476p.

WATERLOW, J.C. The mysteries of nitrogen balance. Nutrition Research Reviews, v.12, p.25-54, 1999.

WATERLOW, J.C. Protein turnover. 2.ed. Wallingford: CABI Publishing, 2006, 313p.

ZERVOUDAKIS, J.T. Suplementos multiplos de auto controle de consumo e freqüência de suplementação, na recria de novilhos durante os períodos das águas e transição águas-secas. 2003. 78f. Tese (Doutorado em Zootecnia) Universidade Federal de Viçosa, Viçosa, MG.

ZERVOUDAKIS, J.T.; PAULINO, M.F.; CABRAL, L.S. et al. Suplementos múltiplos de auto controle de consumo na recria de novilhos no período das águas. Ciência e Agrotecnologia, v.32, p.1968-1973, 2008.

ZORZI, K.; DETMANN, E.; QUEIROZ, A.C. et al. In vitro degradation of neutral detergent fiber of high-quality tropical forage according to supplementation with different nitrogenous compounds. Revista Brasileira de Zootecnia, v.38, p.964-971, 2009. 